\title{
The Influence of External Locus of Control on Life Stress: Evidence from Graduate Students in Thailand
}

Chaiyaset Promsri

\section{Faculty of Business Administration Rajamangala University of Technology Phra Nakhon, Bangkok, Thailand. Email.Chaivaset.p@rmutp.ac.th}

Licensed:

This work is licensed under a Creative Commons Attribution 4.o License.

Keywords:

Locus of control

Life stress

Graduate students.

\begin{abstract}
The purpose of this study was to explore the influence of external locus of control on life stress. A total of twenty-five graduate students from one public university in Thailand participated in data collection. A survey questionnaire was use to gather data from respondents. Results showed that external locus of control had a significant influence on life stress of graduate students at .05 level. Findings indicated that locus of control could explain $15.8 \%$ of variance to life stress of graduate students. Overall, the more external locus of control graduate students had, the more life stressful they experienced. Discussions, limitations, and recommendations for further studies were also conferred.
\end{abstract}

\section{Introduction}

As the business world has tremendously involved and rapidly changed to cope with a highly competitive environment in a digital age, an organization must find the most effective way to run the business in order to gain a sustainable competitive advantage and survival. Learning new concepts and ideas in doing business is considered as one of key success factors that every organization needs to implement and ensures that all employees know how to work exceptionally to make different things happened to the organization. Education and training in distinctive platforms and styles should be delivered to all employees such as in-class training, e-learning, field study, coaching and mentoring, and action learning, etc. Among these methods, providing the opportunity for employees to study in business school to learn and update new business models and cases is viewed as a favorite approach that many organizations has still utilized nowadays. Various organizations provide scholarship and sponsorship for employees to study in MBA program. Pursuing a graduate degree in business area is a great challenge for many employees because they will experience a new world of opportunities beyond their presence. However, studying in graduate level comes with a lot of pressure, which can lead to stress and anxiety. A Recent survey showed that almost $70 \%$ of graduate students had above average level of stress in the last year of their study (Dito, 2018). Previous research found various sources of stress in college students such as thinking upon the future aspects, job, relationships, academic, family, and social (Mazumdar, Gogoi, Buragohain, \& Haloi, 2012). Students have been affected by stress in various conditions such as behavioral, psychological, and psychosomatic factors. These conditions can greatly cause students' academic performance.

To effectively cope with stress, locus of control is considered as a key component Karimi and Alipour (2011). Locus of control is the degree to which people perceive that they have an ability to control over outcomes of behaviors (Goyzman, 2010). Generally, locus of control can be divided into two distinctive forms: internal and external locus of control. Individuals with internal locus of control believe that they are able to control outcomes of behaviors or their destiny. On the other hand, people who have external locus of control believe that they have no direct control over outcomes of behaviors (Sahraian, Omdivar, Ghanizadeh, \& Bazrafshan, 2014; Zaidi \& Mohsin, 2013). However, based on the researcher's experience dealing with numerous graduate students, some graduate students in business program are more likely to believe that their academic performance is somehow relied on the control of external environment. To illustrate a clear picture of this notion, a lot of evidences can be accounted to confirm this belief such as a worship of holy sacred statues to beg for the good academic performance. The superstitious beliefs of college students reflect a highly concern on external locus of control. This notion is contradictory to the past research in which students with internal locus of control had high learning performances while those with external locus of control were more passive and reactive during the learning process (Ozen-Kutanis, Mesci, \& Övdür, 2011). In addition, the latest research found that internal locus of control had a significant effect on students' academic performance rather than external locus of control (Oluseyi \& Olusegun, 2018). The failure of academic performance can cause students' anxieties and stresses. Tyson (1981) found that locus of control had an impact on individual's perception of life stressful events. Abouserie (2006) found similar consequences as students who believed in 
external locus of control were reported more stressed than those with internal locus of control. Additionally, recent research indicated that individuals with internal locus of control had a higher level of stress management than those with external locus of control (Ogolla, Aloka, \& Raburu, 2016). Despite the confirmation of a negative effect of external locus of control on academic performance leading to stress, many students in graduate program have still considered external locus of control as one key factor of their success. To make it clear for graduate students, this study aimed to investigate the effect of external locus of control on life stress in graduate students. The findings of this study could be used not only to enhance a body of knowledge in this field, but also enlighten graduate students' understanding leading to help them change their perception and attitude toward locus of control.

\section{Literature Reviews}

Sadowski and Blackwell (1985) examined the association between locus of control and perceived stress among student-teachers. Data analysis showed that student-teachers who perceived that they could control the teaching environment reported the situations as less stressful than those who believed that they had less control over the events.

Khan, Saleem, and Shahid (2012) studied the relationship between locus of control and stress among 200 college and university lecturers of Bahawalpur in Pakistan by using convenient sampling technique to collect data. This study used Rotter's internal-external LOC Scale developed in 1966 and Stress Questionnaire created by Stress Management Association UK in 2009 as the instrument for data collection. Results of this study indicated that lecturers with high level of internal locus of control had low level of stress. In contrast, instructors with high level of external locus of control had high level of stress. In addition, results also found the significant relationship between locus of control and stress. However, there might be some arguments on the findings of this study since the non-probability sampling technique was used for data collection leading to the questions on the use of inferential statistics for data analysis.

Sahraian et al. (2014) explored the relationship between job stress and perceived locus of control in nurses. Samples were collected from female nurses in Shiraz City State Hospital in Iran. Eliot's Job Stress Questionnaire in 1995 and Rotter's internal and external LOC scale in 1966 were utilized as the scale measurement for data collection. Two-hundred seventy questionnaires were distributed to nurses in the hospital, only 213 of them were returned with completion. To examine the association between job stress and locus of control, linear regression analysis was used. Results demonstrated that occupational stress were significantly correlated with locus of control.

Ogolla et al. (2016) investigated the association between locus of control and stress management. This study gathered data from 169 principals by using stratified sampling technique. Data were collected through the locus of control questionnaire and stress management questionnaire. Findings indicated that principals with internal locus of control had a greater score of stress management than those with external locus of control. Moreover, the ANOVA results showed that there was a statistically significant difference in stress management for locus of control.

According to the literature reviews, it can be concluded that individuals with internal locus of control were less stressful than those who felt that they had less control over the outcomes of their behaviors, as also known as external of control. To confirm the findings of these past studies, in particular the effect of external locus of control on perceived stress, this present study aimed to investigate the association between external locus of control and life stress among graduate students. Therefore, the research hypothesis of this study was proposed as "there was a statistically significant influence of external locus of control on life stress among graduate students."

\section{Methodology}

This empirical study aimed to examine the effect of external locus of control on life stress among graduate students in Bangkok, Thailand. Twenty-five graduate students who registered in MBA program at a selected public university in Thailand participated in this present study. A self-administrated questionnaire was used as the instrument for data collection. Life stressful scale proposed by Robbins, De Cenzo, and Coulter (2015) was utilized to assess life stress of graduate students. This scale measurement consisted of 8 -item of a 5-point rating scale ranging from 1 (strongly disagree) to 5 (strongly agree). External locus of control was developed based on the locus of control concepts proposed by Rotter (1966). To ensure the quality of these instruments, content validity with index objective congruence (IOC) method and reliability with Cronbach's alpha test were conducted. The IOC scores indicated a high validity of the scale measurement, which scores of all items of both scales were greater than 0.5. Additionally, internal consistencies of these scale measurements had acceptable alpha scores, as shown in Table 1 (Nunnally, 1978). Linear regression analysis was used to examine the effect of external locus of control on life stress among graduate students. Linear regression analysis was suitable to use to test the research hypothesis since analysis of regression was required at least 20 samples per independent variable (Statistics Solution, 2018). 
Table-1. Reliability Coefficients of External Locus of Control and Life Stress.

\begin{tabular}{l|c|c}
\hline Scale Measurement & Number of Items & Alpha Scores \\
\hline External Locus of Control & 8 & 0.625 \\
\hline Life Stress & 8 & 0.791 \\
\hline Source: & 8 & \\
\hline
\end{tabular}

Source: Developed by Author.

\section{Results}

To test whether external locus of control can predict life stress of graduate students, simple linear regression was used. To check the appropriateness of using linear regression, Shapiro-Wilk Test of normality was calculated because this test was suitable for small sample size (Cronk, 2012). The value of the ShapiroWilk Test was 0.792 , which means that dependent variable in this study (life stress) was normally distributed. Also, this study used the output of a normal Q-Q plot to graphically determine normality. The plot indicated that data were normally distributed as the data points were close to the diagonal line. A significant regression equation was found $(\mathrm{F}(1,25)=4.377, \mathrm{p}<.05)$, with an $\mathrm{R}^{2}$ of .158 . This result designated that external locus of control could explain $15.8 \%$ of variance to life stress of graduate students Table 2 . This suggested that there were other variables that could explain life stress of these respondents that had not been encompassed in this study. Overall, graduate students' life stress is equal to 1.219+.549(External locus of control). Hence, research hypothesis of this present study was confirmed.

Table-2. Simple Linear Regression of External Locus of Control on Life Stress

\begin{tabular}{|c|c|c|c|c|c|}
\hline Model & \multicolumn{2}{|c|}{ Unstandardized } & Standardized & \multirow[t]{2}{*}{$\mathbf{t}$} & \multirow[t]{2}{*}{ Sig. } \\
\hline 1 & $\mathbf{B}$ & S.E. & Beta & & \\
\hline (Constant) & 1.219 & .934 & & 1.306 & .205 \\
\hline ExLOC & .549 & .261 & .396 & 2.068 & $.05^{*}$ \\
\hline $\begin{array}{l}\mathrm{n}=25 \\
\mathrm{R}=.398\end{array}$ & \multicolumn{2}{|c|}{$\begin{array}{ll}\mathrm{df}=1 & \mathrm{~F}=4.377 \\
\text { Durbin-Watson }=\mathbf{2 . 0 8 2}\end{array}$} & $\mathrm{R}^{2}=.158$ & \multicolumn{2}{|c|}{ Adjusted $R^{2}=.120$} \\
\hline
\end{tabular}

\section{Conclusion, Discussions, and Recommendations}

This study aimed to scrutinize the influence of external locus of control on life stress among graduate students. Findings indicated that the more external locus of control graduate students had the greater life stressful they felt. Results of this present study support the research hypothesis that external locus of control had a statistically significant effect on life stress, and confirm the findings of past studies in which relationship between these two variables were found (Abouserie, 2006; Khan et al., 2012; Ogolla et al., 2016; Sadowski \& Blackwell, 1985; Sahraian et al., 2014; Tyson, 1981). This can be explained that graduate students who believe that their success or failure depends on the external environment rather than internal environment, they are more likely to experience more stressful life. As a consequence, they are more likely to accuse uncontrollable factors and events as the cause of their failure. Graduate program needs to take the step to assist these graduate students to learn how to change their attitude and develop a strong belief in their ability to control outcomes of their behaviors.

For the limitation, this study had a small sample size of graduate students, which affected the generalizability of the study. Expansion of sample size is recommended for the further study. In addition, this study confined its focus on external locus of control solely, which may not entirely describe the concept of locus of control. Hence, the future research should add internal locus of control to investigate the relationship between locus of control and life stress.

\section{Acknowledgement}

I am very thankful to Rajamangala University of Technology Phra Nakhon for facility support and sponsorship for publication.

\section{References}

Abouserie, R. (2006). Sources and levels of stress in relation to locus of control and self- esteem in university students. An International Journal of Experimental Educational Psychology, 14(3), 323-330.

Cronk, B. C. (2012). How to use SPSS statistics: A step-by-step guide to analysis and interpretation (7th ed.). Glendale, CA: Pyrczak Pub.

Dito, C. (2018). 5 tips for grad school stress. Retrieved from https://gsm.ucdavis.edu/blog/5-tips-grad-school-stress.

Goyzman, J. (2010). The influence of locus of control and stress on performance. Retrieved from https://ir.lib.uwo.ca/cgi/viewcontent.cgi? article=1014\&context=hucjlm.

Karimi, R., \& Alipour, F. (2011). Reduce job stress in organizations: Role of locus of control. International Journal of Business and Social Science, 2(18), 232-236.

Khan, A. A., Saleem, M., \& Shahid, R. (2012). Buffering role of locus of control on stress among the college/university teachers of Bahawalpur. Pakistan Journal of Commerce and Social Sciences (PJCSS), 6(1), 158-167.

Mazumdar, H., Gogoi, D., Buragohain, L., \& Haloi, N. (2012). A comparative study on stress and its contributing factors among the graduate and post-graduate students. Advances in Applied Science Research, 3(1), 399-406. 
Nunnally, J. C. (1978). Psychometric theory. New York: McGraw-Hill.

Ogolla, P., Aloka, P., \& Raburu, P. (2016). Relationship between locus of control and stress management among high school principals Kenya. International Journal of Applied Psychology, 6(5), 150-155.

Oluseyi, A. D., \& Olusegun, O. F. (2018). Influence of emotional intelligence and locus of control on academic achievement of underachieving high ability students. Journal for the Education of Gifted Young Scientists, 6(2), 14-22.

Ozen-Kutanis, R., Mesci, M., \& Övdür, Z. (2011). The effects of locus of control on learning performance: A case of an academic organization. Journal of Economic and Social Studies, 1(2), 113-136.

Robbins, S. P., De Cenzo, D. A., \& Coulter, M. (2015). Fundamentals of management: Essential concepts and applications (9th ed.). New York: Prentice Hall

Rotter, J. (1966). Generalized expectencies for internal versus external control of reinforcement. Psychological Monographs, $80(1), 1-28$.

Sadowski, C. J., \& Blackwell, M. W. (1985). Locus of control and perceived stress among student-teachers. Psychological Reports, 56(3), 723-726.

Sahraian, A., Omdivar, B., Ghanizadeh, A., \& Bazrafshan, A. (2014). Association of job stress with locus of control in nurses. Shiraz E-Medical Journal, 15(2), e20588.

Statistics Solution. (2018). Assumptions of linear regression. Retrieved from http://www.statisticssolutions.com/assumptions-of-linear-regression/.

Tyson, G. (1981). Locus of control and stressful life events. South African Journal of Psychology, $11(3), 116-117$.

Zaidi, I. H., \& Mohsin, M. N. (2013). Locus of control in graduation students. International Journal of Psychological Research, $6(1), 15-20$. 